\title{
0 Estado (de Bem-Estar Social) como Ator do Desenvolvimento: Uma História das Ideias*
}

\author{
Celia Lessa Kerstenetzky ${ }^{1}$ \\ Jaques Kerstenetzky ${ }^{2}$ \\ ${ }^{1}$ Universidade Federal Fluminense (UFF), Niterói, RJ, Brasil. E-mail: celiakersten@gmail.com \\ ${ }^{2}$ Universidade Federal do Rio de Janeiro (UFRJ), Rio de Janeiro, RJ, Brasil. E-mail: \\ jkersten@gmail.com)
}

\section{INTRODUÇÃO}

$\mathrm{O}$ tema do Estado como ator do desenvolvimento é paradoxalmente tão vasto quanto subteorizado. De fato, a ausência de um corpus teórico único e coerente convive com um grande número de ideias e práticas, refletindo a fragmentação da experiência, a pluralidade de perspectivas e a diversidade de campos disciplinares que dele se ocupam. Ao contrário de lamentar esse estado de coisas, nossa narrativa particular beneficia-se da riqueza dessa ampla reserva de ideias e busca organizar o campo de interesse em torno de uma noção ampla de Estado desenvolvimentista como sendo aquele que, seja por meio de políticas pragmáticas, seja de planos ambiciosos, persegue o bemestar, e não meramente o poder, e muito menos o mal-estar.

Ao optarmos por esse enquadramento, estamos deliberadamente nos afastando de narrativas convencionais que tematizam o Estado desenvolvimentista exclusivamente como agente do desenvolvimento econômico, tomando como automática a conversão deste em bem-estar, bem como de narrativas que negligenciam o aspecto evolucionário da própria noção de desenvolvimento, que se modifica no tempo históri-

\footnotetext{
* Versões anteriores deste artigo foram apresentadas em vários eventos e receberam os comentários de Bruce Currie-Alder, David Malone, Carlo Panico, José Reis, José Caldas, Marta Arretche, pelos quais agradecemos. Somos gratos ainda a um parecerista anônimo de DADOS - Revista de Ciências Sociais.
}

DADOS - Revista de Ciências Sociais, Rio de Janeiro, vol. 58, no-3, 2015, pp. 581 a 615. 
co em resposta a experiências, repertórios ideacionais e, evidentemente, embates. O enquadramento aqui sugerido como ponto de partida é suficientemente amplo, e mesmo propositalmente vago, para acomodar um variado e mutante conjunto de concepções de Estado desenvolvimentista. Nesse percurso, à luz de concepções atuais que enfatizam a multidimensionalidade do desenvolvimento, acabamos por recuperar os Estados de bem-estar social modernos como atores centrais na promoção de desenvolvimento.

Nossa narrativa, vale insistir, se ocupa de concepções de Estado desenvolvimentista, recorrendo a experiências concretas apenas na medida em que estas são portadoras de visões específicas e identificáveis daquele e, portanto, ocasião para a avaliação crítica de estilos de intervenção. A "autoria" dessas concepções é atribuída tanto a economistas, cientistas políticos, historiadores e sociólogos econômicos, quanto a burocracias governamentais e de organismos internacionais, e organizações políticas como os partidos.

Adotando uma perspectiva evolucionária, começamos registrando brevemente uma mudança seminal de visão acerca das formas de Estado, de "Estado-poder" a "Estado desenvolvimentista", e justificativas para o progressivo envolvimento de Estados nacionais na transformação econômica de países ao longo dos séculos XVIII e XIX. Nessa seção, observamos que Estados nacionais foram revestidos da "missão desenvolvimentista" em argumentos políticos, mas que o mesmo se passou em argumentos econômicos, especialmente no pós-Segunda Guerra Mundial: de um lado, a transformação econômica era vista como precondição para a construção e fortalecimento de Estados nacionais; de outro, intervenções estatais eram concebidas como essenciais para a superação do atraso econômico.

Porém, a crescente percepção de insucesso da arquitetura desenvolvimentista conduzida pelo Estado em países tardios e medida em termos de catch up econômico é a senha para a produção de novas interpretações e contrastes ao longo das últimas décadas do século XX e início do século XXI. Na seção Politizando o Estado para a transformação econômica, apontamos uma oscilação de percepções sobre a intervenção: de inicialmente positivas a negativas - motivadas por taxas de crescimento não sustentáveis e insuficiente promoção de bem-estar - e de volta a positivas. Nessa seção, a novidade é a (re)politização do Estado que, sublimada nas abordagens tradicionais da economia do desenvolvimen- 
to e demonizada nas perspectivas liberais, acaba finalmente por vir à tona na identificação de trajetórias baseadas seja em conexões com as elites econômicas (empresários/negócios), seja em participação mais ampla e efetiva de estratos não elite (populares / sociedade civil) da população. Uma abordagem mais explicitamente política do Estado desenvolvimentista introduz (formas de) democracia como objeto de atenção e identifica o Estado de bem-estar social como forma de Estado crítica para a promoção da transformação econômica.

A seção seguinte apresenta uma perspectiva normativa que, ao propor uma concepção multidimensional de desenvolvimento, envolvendo aspectos econômicos, sociais e políticos, dialoga com aspirações e insatisfações detectadas na sequência evolutiva. São, então, revisitadas as objeções da "abordagem das capacitações" de Amartya Sen ao desenvolvimento entendido como transformação econômica e à visão alternativa do desenvolvimento como transformação social, na medida em que estas distintas visões trazem consequências para modelos de Estado (de bem-estar) desenvolvimentista. Em particular, são apresentadas visões de desenvolvimento mediado e não mediado pelo crescimento econômico. Em seguida, uma breve apresentação do modelo socioeconômico dinamarquês ilustra novos caminhos e estratégias de expansão de capacitações nas décadas recentes dentro de uma concepção multidimensional de desenvolvimento. Finalmente, conclui-se com a sugestão de temas para reflexão futura.

Uma última advertência: o texto não tem a pretensão de versão única e exaustiva e sequência infalível de ideias (várias ideias abandonadas em nossa sequência seguem vivas e férteis dentro dos nichos epistêmicos em que foram concebidas). Procuramos fazer sentido de ampla variedade de percepções e concepções sobre o Estado desenvolvimentista por meio de uma narrativa evolucionária, em que cada nova alternativa engendra novos problemas e encoraja reações e contrastes, muitos dos quais não antecipáveis. Embora nossa história se interrompa em um "máximo local", não há garantia de que novas tensões não abalem certezas estabelecidas. Algumas dessas tensões já se anunciam, como apontamos nas conclusões do artigo.

\section{TRANSFORMAÇÃO ECONÔMICA E AÇÃO DO ESTADO}

Relatos das origens do Estado moderno apontam o Tratado de Westfália de 1648 como marco histórico da conformação do mundo como um 
sistema de Estados nacionais. Apesar de seu significado mais amplo ser aberto à disputa, é geralmente aceito que o Tratado teria formalizado a soberania do Estado sobre o seu território, perante sejam vizinhos sejam residentes no interior de suas fronteiras geográficas, desse modo reduzindo a limites manejáveis as ameaças externas, a fragmentação política interna baseada em religião ou outras clivagens e as inevitáveis combinações entre esses elementos. No mínimo, o Tratado gerou a expectativa legítima desse reconhecimento, cuja violação justificaria o uso da violência por parte do Estado.

Expansões desta noção de Estado-poder incluíram mais tarde limites legais a serem impostos ao soberano (como já presentes nas qualificações ao poder soberano em Jean Bodin, mas principalmente na separação de poderes em John Locke) e a noção, disseminada com o iluminismo e a Revolução Francesa, de que poder implicaria responsabilidades. De fato, a noção de que os assuntos de Estado ultrapassam a defesa e a ordem para incluir também a garantia de liberdades e de bem-estar de indivíduos no território e mesmo assistência e trabalho quando necessário encontra-se claramente expressa, por exemplo, no artigo XXI da Declaração Francesa dos Direitos Humanos de 1793. E mesmo visões liberais de ordem natural que emergiram de ambos os lados do Canal da Mancha no mesmo século XVIII representaram o sistema legal em sua capacidade de assegurar liberdades individuais e assistência pública como pilares desta ordem.

De acordo com estudos histórico-comparativos, obrigações positivas e negativas do Estado provocaram seu envolvimento na transformação econômica de países, entre outros motivos, para assegurar receitas e favorecer interesses convergentes com propósitos do Estado (Chang, 2002; Evans, 1995; Heckscher, 1935). Evidências fortes deste desenvolvimento foram as políticas mercantilistas adotadas na Europa e as políticas industriais e comerciais amplamente utilizadas para assistir às indústrias nascentes no processo de catch up britânico e na revolução industrial no século XIX, conforme fartamente documentado em Chang (2002), na contramão de interpretações de tipo laissez-faire para o desenvolvimento inglês.

Com a Restauração Meiji no Japão (1868-1911), contudo, a transformação econômica assistida pelo Estado, que até este ponto estivera principalmente motivada por receitas, encontrou um novo estilo. Forçado a abrir seu comércio e com capacidades empresariais insuficientes, o Japão recorreu a políticas industriais como peça central de sua estratégia 
de mudança estrutural que levou o Estado a desempenhar os papéis de empresário, financiador, facilitador, coordenador e regulador de atividades econômicas (Wade, 2003; Chang, 2002). A transformação econômica (industrial), por sua vez, pareceu dar suporte não apenas à prosperidade material como à autodeterminação do país no âmbito do sistema de Estados nacionais.

Trilhando um caminho exitoso após a Segunda Guerra Mundial com o experimento MITI, o poderoso e operoso Ministério de Comércio Internacional e Indústria (Johnson, 1982), o Japão estabeleceu um exemplo a ser seguido por outros países no século XX, em especial por aqueles que, como a Coreia do Sul, empreenderam esforços de desenvolvimento como forma de afirmação e fortalecimento de seus Estados nacionais, após humilhantes experiências coloniais, devastação provocada por guerras e enfraquecimento da autonomia política pela condição de nações derrotadas. Nesse contexto, projetos de desenvolvimento econômico foram instrumentalizados para afirmar alguma medida de autodeterminação política.

Envolvidos no processo de transformação de economias agrárias em industriais, os Estados nacionais se diferenciariam ainda quanto ao planejamento das mudanças. Alguns estabeleceram planos de desenvolvimento com objetivos explícitos e coerentes, estratégias e agências de coordenação, ao passo que outros, sendo não planejadores nesse sentido, conduziram políticas industriais, comerciais e tecnológicas em bases pragmáticas (Inglaterra, Alemanha, França e países escandinavos do pré-guerra). Dentre os planejadores, alguns foram holísticos, com plano abrangente, mas deficiente em mecanismos de feedback (União Soviética e países do Leste Europeu); outros adotaram modelos mais gradualistas, com espaço para experimentação e aprendizado (Japão pós-Meiji, Coreia, Taiwan, e a maioria dos países hoje desenvolvidos no pós-guerra). Não surpreende que a necessidade de planejamento tenha sido mais intensamente sentida por países que tinham longo caminho a percorrer para alcançar os líderes industriais.

Porém, se parece claro por que a busca de prosperidade material teria capturado a imaginação dos governantes - sendo autofinanciamento, autodeterminação e legitimidade interna as razões com candidatura mais forte -, permanece ainda a necessidade de compreender, tanto nos casos concretos como na teoria, de que maneiras e por quais razões seria o Estado necessário para a transformação econômica. De um modo ou de outro, muitos países tornaram-se planejadores após a Se- 
gunda Guerra Mundial, e enquanto isto foi motivado pela reconstrução naqueles diretamente envolvidos, foi com a construção a partir do zero no caso de nações limitadamente ou recentemente independentes que escaparam à destruição da guerra (Judt, 2005). Que argumento "econômico" poderia ser invocado para o envolvimento do Estado?

De fato, foi na altura do segundo pós-guerra que o "problema do desenvolvimento" chamou a atenção dos economistas e a "economia do desenvolvimento" emergiu como campo teórico autônomo.

Desenvolvimento econômico, em uma primeira aproximação, significou ampliação do produto doméstico; assim, modelos de crescimento (como os de Harrod-Domar e de Solow) que identificavam a acumulação de capital como requisito para mudança econômica poderiam ser de utilidade. No entanto, tais modelos, representando a transformação econômica como consequência natural e cumulativa de alocações de mercado sob dotações dadas, se aplicavam originalmente a países que se industrializaram cedo. Essa especificidade motivou a emergência de abordagens teóricas adicionais que, visualizando um processo de transformação descontínua em economias atrasadas, melhor serviriam ao caso de países "subdesenvolvidos". Trata-se das assim chamadas teorias da primeira geração de economistas do desenvolvimento (Agarwala e Singh, 1958). Na maioria das versões, a mudança estrutural, entendida como industrialização, requer intervenção do Estado para coordenar investimentos que, devido a externalidades, não se materializariam via forças de mercado.

Notadamente, uma ramificação latino-americana emergiu no âmbito da Comisión Económica para América Latina y el Caribe (Cepal) sob a liderança do economista argentino Raúl Prebisch, em um caso de interação de mão dupla entre teoria e prática: a escola da Cepal, através de sua descrição do subdesenvolvimento latino-americano indutiva e orientada para ação, influenciou formuladores de política, empresários e intelectuais da região (Bielschowsky, 2009) em uma época em que muitos países experimentavam a industrialização por substituição de importações com graus variados de sucesso.

Ao mesmo tempo que o desenvolvimento era escrutinado pela economia, dando lugar a justificativas analíticas para a ação econômica do Estado, a necessidade do Estado era reforçada por observação histórica sistemática como a empreendida notoriamente pelo historiador Alexander Gerschenkron (1962). O autor identificou na Europa do sé- 
culo XIX um contínuo de situações no qual instituições como o Estado eram instrumentais para a superação do atraso econômico. Enquanto em um extremo estava a Alemanha, onde bancos universais cumpririam a função de coordenação de investimentos, em outro estavam os casos de extremo retardo, como Rússia e países do Leste Europeu, nos quais empresários, força de trabalho disciplinada e financiamento estiveram ausentes, e requereram intervenção intensiva e extensiva do Estado.

Mais tarde, esta descrição nuançada do ativismo estatal iria, juntamente com teorias estruturais, fertilizar abordagens histórico-institucionais das últimas décadas do século XX, capitaneadas por economistas políticos e sociólogos econômicos (Hirschman, 1958; Herrick e Kindleberger, 1983; Evans, 1995; Chang, 2002). Teorias econômicas estruturalistas também acabariam por influenciar teorias neoestruturalistas mais recentes (Lin, 2011), que defendem a ação estatal como complemento da alocação feita pelo mercado, aceitando, pois, a ideia da necessidade do Estado para transitar de um estágio de desenvolvimento a outro, já que o desenvolvimento reconhecidamente envolveria mudanças de escala, infraestrutura e tecnologia, ainda que mantendo as referências ortodoxas de primado da competição, dotação de fatores, vantagens comparativas e soluções ótimas.

Ao fim e ao cabo, com exceção da visão que defende tão somente a ação de mercados, a necessidade do Estado na transformação econômica encontrou justificativa em uma variedade de perspectivas, com muito do pensamento teórico resultando da observação das práticas de desenvolvimento, mais do que a teoria influenciando a prática, embora maneiras indiretas de difusão de teorias não devam ser subestimadas, como o caso da Cepal parece sugerir.

A próxima questão se refere a que capacidades do Estado estiveram envolvidas. Embora não atraindo muita atenção na economia, esta questão teve considerável ressonância em estudos histórico-institucionais. Cabe comentar que a desatenção da economia tem uma de suas raízes na influência da teoria da escolha pública, a qual notoriamente adverte sobre os perigos de captura do Estado por agentes privados maximizadores e sobre ser o interesse público não mais do que interesse privado disfarçado (Krueger, 1990) ${ }^{1}$. Outros contestariam o sequitur, como veremos mais adiante. Mas, não apenas: outra raiz pode ser encontrada na própria economia do desenvolvimento que mesmo em sua vertente es- 
trutural é silente em relação ao problema das capacidades do Estado, o qual é retido mecanicamente, como algo eventualmente necessário e que se materializará na ocasião propícia. Em contraste, estudos histórico-institucionais adotaram uma abordagem mais sutil e se puseram a identificar as reais capacidades do Estado, mobilizadas nas diversas experiências, as conexões de fato estabelecidas entre o aparato estatal e setores sociais para o grande salto da industrialização e seus efeitos perceptíveis.

As primeiras contribuições foram os estudos da decolagem de países do Leste Asiático nos anos 1960 e 1970 (Johnson, 1982; Amsden, 1989; Chang, 2002; Wade, 2003) que deram origem ao difundido conceito de "Estado desenvolvimentista" (Johnson, 1982) ${ }^{2}$. Essas experiências, ricas em inovações, se abririam a diferentes interpretações. Assim, enquanto para o Banco Mundial, em um relatório de 1993, os tigres asiáticos ilustravam o funcionamento benigno das livres forças de mercado, os estudos histórico-institucionais identificavam ação estatal pervasiva e multiforme, menos em propriedade e controle de empresas, mais na função de facilitar o florescimento do capital privado (World Bank, 1993). Como resultado, as experiências estimularam uma análise refinada dos aspectos de estrutura e agência do Estado. Dentre os aspectos identificados, destacaram-se a presença de uma burocracia weberiana autônoma, coerente e coesa, e conexões do Estado com a sociedade civil, especialmente com empresários, ou "sinergia" (Evans, 1995).

As experiências permitiriam ainda rastrear papéis diferenciados do Estado, autônomo porém conectado, nos processos de transformação: custódio, demiurgo, parteiro e pastor (Evans, 1995), na medida em que o Estado teria atuado, respectivamente, como regulador, proprietário, promotor ou facilitador em relação ao capital privado. Enquanto as primeiras experiências de industrialização haviam se assentado mais em papéis regulatórios e as intermediárias em Estados empresários, experiências posteriores, como Coreia e Taiwan, optaram pela promoção de grupos privados através de crédito e outras intervenções de facilitação. De forma geral, é a existência de certas precondições o que define o papel apropriado: burocracia e conexões em combinação com circunstâncias externas, as quais em diferentes ocasiões indicariam os setores dinâmicos (Evans, 1995). Em suma, mesmo se o protagonismo estatal é retido, dentro da tradição de Gerschenkron, não há papel, setores específicos ou conjunto de políticas advogados de forma abstrata em relação a circunstâncias, capacidades e conexões reais do Estado. 
No entanto, posto que as análises entendessem os projetos de desenvolvimento como equivalentes à industrialização de países, as relações entre Estado desenvolvimentista e sociedade se resumiriam a ligações entre burocracia estatal e capital privado, ou seja, conexões com a elite econômica, um passo conceitual que colocaria novos problemas. Apesar de em alguns casos a falta de uma burocracia autônoma e capacitada ter contribuído para impedir um processo de crescimento sustentado, como no Brasil dos anos 1970 e 1980, em outros, como na Coreia nas mesmas décadas, onde uma burocracia capaz e autônoma esteve presente, estratégias de desenvolvimento de cima para baixo isolaram a burocracia da influência e controle de amplos setores da população (o que também ocorreu no Brasil). Não surpreende, então, que a "sinergia" da industrialização terminasse por fazer brotar preocupações e protestos contestando a legitimidade da trajetória particular empregada para a acumulação de capital, sobretudo quando o modelo econômico passa a dar sinais de fadiga. O intenso debate em torno do tipo de legitimidade que se pode obter quando o processo de desenvolvimento é conduzido por um Estado autoritário em conexão íntima com a elite econômica ilustra o mal-estar que por fim estimulou a revisão dos elementos mais propriamente prescritivos dessa abordagem (Johnson, 1999).

Em consequência, emerge a questão a respeito de quais os meios apropriados para a definição do conteúdo do interesse público em contextos de desenvolvimento. Na próxima seção exploramos duas perspectivas alternativas, confrontando mercado e democracia: a visão da teoria da escolha pública (com seu ceticismo em relação à vida política) e a visão institucional das potencialidades das experiências democráticas.

\section{POLITIZANDO O ESTADO PARA A TRANSFORMAÇÃO ECONÔMICA}

\section{Retirando o Estado}

A partir dos anos 1980, duas circunstâncias contribuíram para o descrédito da intervenção do Estado para a transformação econômica. A primeira e mais importante tem relação com as experiências de acumulação de capital conduzidas pelo Estado que, embora tenham levado ao crescimento econômico, não se traduziram em crescimento sustentado, e menos ainda em bem-estar, frustrando expectativas teóricas e promessas políticas. Isto foi particularmente o caso de países latino-americanos, africanos e do sul da Ásia, que experimentaram trajetórias de crescimento não sustentadas, com desigualdade crescente 
e/ou pobreza e lenta melhoria de indicadores sociais durante a industrialização por substituição de importações conduzida pelo Estado nos anos 1960 e 1970 (Lin, 2011; Sen, 1983), seguidas da crise da dívida nos anos 1980. E, embora análises histórico-institucionais fossem argumentar que as trajetórias falhas tinham raízes na ausência de capacidades estatais apropriadas e em conexões frágeis com a sociedade civil (Evans, 1995), o novo estado de espírito, reverberando o mantra da teoria da escolha pública, fez recair a responsabilidade sobre a intervenção econômica do Estado, por interferir no funcionamento das forças de mercado e criar oportunidades de captura e má economia política.

A segunda circunstância se liga à estagflação e à crise fiscal, difundidas pelo mundo desenvolvido a partir do início dos anos 1970 e ao longo da década seguinte, e ao prestígio granjeado pela teoria das expectativas racionais, resultando na atribuição de tais problemas à má gestão fiscal e monetária por parte dos governos. Apesar de os problemas serem de naturezas diferentes e se abrirem para diagnósticos alternativos, a visão predominante, sobretudo nos organismos internacionais multilaterais, foi a do diagnóstico único: a culpa é do Estado.

Sob este novo clima ideológico emergiu a segunda geração de economistas do desenvolvimento, desta vez de dentro da economia neoclássica, argumentando enfaticamente que o desenvolvimento requeria a reinstauração dos mecanismos de mercado e o correto rearranjo de todas as políticas (getting all policies right) (Meier, 2001): liberalizar o comércio e o investimento estrangeiros, aplicar programas de estabilização, privatizar empresas estatais e restaurar o sistema de preços.

O Chile está entre os primeiros países influenciados por esta vertente de pensamento. Corrigiu suas políticas (no sentido acima) com relativo sucesso se as taxas de crescimento são o foco, mas com resultados negativos se as desigualdades e a ausência de democracia forem incluídas na fatura (Solimano, 2012). Ainda mais significativo foi o redirecionamento da política de empréstimos do Banco Mundial, acompanhando a substituição do economista-chefe Hollis Chenery, da primeira geração de economistas do desenvolvimento, por Anne Krueger, da segunda geração, em 1982: a certa altura, países devedores estavam pagando mais do que se beneficiando dos empréstimos (Goldman, 2005). Ainda assim, no final da década de 1980, e apesar de crítica contundente em um importante relatório do Fundo das Nações Unidas para a Infância (Unicef) documentar graves danos à saúde e à educação de crianças do Terceiro Mundo associados a programas de ajusta- 
mento (Goldman, 2005), prevaleceu a ideia de "retificação" das políticas, que foi absorvida no conjunto de dez recomendações do "Consenso de Washington" (Williamson, 1990).

Com o tempo, problemas persistentes de desempenho econômico, crescimento fraco ou nenhum crescimento, volatilidade, pobreza e desigualdade, na sequência da adoção das recomendações, ao mesmo tempo que seguiram fomentando crítica e protesto, tiveram o efeito de voltar a atenção das organizações financeiras internacionais para as instituições dos países em desenvolvimento. A Nova Economia Institucional (Williamson, 1985) já vinha há certo tempo argumentando que mercados não emanam do vácuo. Sua explicação da trajetória de desenvolvimento de países industrializados (North, 1990) e a desastrada construção de economias de mercado das cinzas das sociedades socialistas do Leste Europeu contribuíram para tornar claro que, para o bem e para o mal, as instituições importam.

Apesar da incerteza teórica acerca de quais instituições se qualificam como adequadas (Bardhan, 2005), as instituições de países em desenvolvimento, na medida em que eram vistas como diferindo daquelas existentes em países desenvolvidos nos quais os mercados prosperavam, tornaram-se o objeto de diferentes recomendações de reforma (Williamson, 2004; Singh et al., 2005). Uma lista expandida de recomendações incluindo liberalização de mercados de trabalho, padrões e códigos financeiros, independência do Banco Central, eliminação de controles de capital, boas práticas de governança corporativa e políticas sociais focalizadas foi incorporada ao arsenal de reformas das instituições financeiras internacionais (Williamson, 2004; Rodrik, 2006). No entanto, ao fim de uma década de reforma fracassada (os anos 1990), uma reavaliação contida no relatório de desenvolvimento do Banco Mundial de 2005 reconheceu que as recomendações deveriam definitivamente afastar-se da norma universal (one size fits all rule), enfatizando menos a eficiência e mais a dinâmica do crescimento (Rodrik, 2006). No mesmo ano, no entanto, o FMI (Fundo Monetário Internacional) reitera sua orientação, admoestando os países sob sua tutela que tentem com mais afinco (try harder) (Singh et al., 2005).

\section{Reintroduzindo o Estado}

A perspectiva do Banco Mundial (Lin, 2011) mencionada na seção anterior, o chamado neoestruturalismo, que recupera o papel do Estado como complementar às forças de mercado, é uma indicação da busca de 
novas maneiras de abordar o desenvolvimento no âmbito dos organismos internacionais face ao fracasso do fundamentalismo de mercado.

Outra indicação vem de um desdobramento de ideias provenientes do próprio campo neoinstitucionalista e do interior da comunidade acadêmica que influencia o Banco Mundial, sugerindo uma alternativa contextual ao "institucionalismo universal", que até então prevalecera naqueles organismos, e se aproximando do institucionalismo histórico de Evans, Amsden e Chang, entre outros. Esta nova perspectiva, mesmo admitindo que algo dera errado com a intervenção estatal nos casos falhos de desenvolvimento, argumenta que aos países deveria ser permitido construir suas próprias soluções institucionais a problemas de desenvolvimento conforme sua própria percepção, e com base em suas experiências e circunstâncias (Rodrik, 2000; Pritchett et al., 2010). Enquanto institucionalistas históricos, como Chang, observariam que nem mesmo os países hoje desenvolvidos teriam criado as instituições recomendadas pelos organismos oficiais quando estavam se preparando para o takeoff - e que, portanto, muitas das instituições teriam sido mais consequência do que causa do desenvolvimento (Chang, 2002) -, outros, a partir de um dissenso interno à comunidade institucionalista de policy dos organismos multilaterais, elaborariam perspectivas mais "comunitaristas" ou diretamente "políticas" como alternativas ao institucionalismo universal.

Na primeira dessas vertentes, a superação dos problemas para o desenvolvimento, incluindo aqueles gerados pela própria intervenção estatal, seria encaminhada com ênfase em projetos representando soluções enraizadas no ambiente de sua aplicação. Seria algo como um caminho do meio entre o modelo de grandes projetos concebidos à semelhança das melhores práticas e modelos organizacionais de países desenvolvidos, que terminam por falhar em países não desenvolvidos pela insuficiência de recursos de implementação para alcançar o funcionamento ideal, e o de pequenos projetos de comunidades ou grupos, que apesar de alcançarem sucesso não são capazes de se replicar nem alcançar escala. O caminho do meio teria concepção modular, contemplaria aprendizado organizacional com metas flexíveis e realistas no lugar de padrões de países desenvolvidos, com genuíno comprometimento, compartilhamento de soluções, capacidades de implementação e prestação de contas se desenvolvendo ao longo do processo (Pritchett et al., 2010; Pritchett e de Weijer, 2010). Na outra versão, tratar-se-ia de aprofundar as democracias (Rodrik, 2000): não importa- 
ria tanto a escala dos projetos, se locais ou nacionais, e sim o regime democrático, em particular se der voz efetiva aos segmentos não elite da população, com genuína experimentação de desenvolvimento podendo ocorrer.

Empiricamente, enquanto a primeira vertente pode não mais que relatar experiências avulsas de sucesso, a vertente política foi capaz de documentar uma grande amostra de casos nos quais a democracia "participativa" superou regimes alternativos na promoção de crescimento, em especial crescimento estável, previsível, persistente e mais igualitário (Rodrik, 2000). Aparentemente, regimes democráticos com mais intensa participação de não elites no processo decisório superaram outros tipos de arranjos políticos na qualidade de mecanismos de agregação de preferências, reunião de conhecimento e livre experimentação e ajustamento de soluções institucionais.

A intervenção do Estado, que esteve sob forte suspeita por conta da crítica empreendida pela teoria da escolha pública, ganhou novo alento com esse desdobramento no campo institucionalista. De fato, ao estabelecer democracias mais participativas como um enquadramento mais apropriado para a definição do "interesse público" e das prioridades do desenvolvimento, a perspectiva de aprofundamento democrático contribui com um argumento de efetividade para a reabilitação da dimensão política, não meramente burocrática, do Estado no pensamento desenvolvimentista. Nessa capacidade, ela contrasta distintamente com abordagens que dão ênfase a conexões das burocracias planejadoras com a elite (Johnson, Woo-Cumings, Amsden) ou ao mercado com redução do papel do governo na alocação de recursos (Krueger).

De certo modo, a análise de histórias de sucesso de países desenvolvidos, nas quais o alinhamento de acumulação de capital, crescimento sustentado e bem-estar basicamente ocorreu, complementa o argumento de efetividade da democracia no experimento desenvolvimentista com um argumento de legitimidade. Embora não seja esta a interpretação canônica em teorias econômicas do desenvolvimento, é notoriamente reconhecido que, nesses casos, a transformação econômica foi assistida por ampla negociação da distribuição de seus bônus: um Estado de bem-estar social politicamente negociado coevoluiu com a democracia, ajudando a difundir bem-estar por meio de redistribuição e de provisão de bens públicos, ao mesmo tempo em que a economia se 
expandia (uma das hipóteses em Kuznets (1955) para explicar a queda da desigualdade simultânea ao crescimento). De fato, como analistas políticos observaram (Berman, 2006; Schmitter, 1974; Streeck, 2009), na Europa continental a nova forma de Estado tanto era um conjunto de políticas sociais de compartilhamento de riscos e provisão de serviços, quanto se configurava como um mecanismo extraparlamentar de expressão de demandas organizadas de elites e não elites, evoluindo conjuntamente com o sistema político. Os casos da Alemanha, país pioneiro do Estado do bem-estar, e da Coreia, um Estado do bem-estar emergente, ilustram bem este ponto, como descrevemos a seguir.

A Alemanha de Otto Von Bismarck passou por mudanças aceleradas, não só na industrialização e urbanização, como na demografia e no sistema político. Nas últimas décadas do século XIX, a seguridade social foi proposta pelo governo conservador em busca de controle social e neutralização da penetração socialista. A partir de sua introdução, o sistema de bem-estar evoluiu como resultado de negociação de classes e representação parlamentar, com a política social se estabelecendo com base em contribuições do capital e do trabalho, se estendendo para além dos trabalhadores industriais a outras ocupações, assumindo novas formas e maiores benefícios. O sistema de bem-estar foi, pois, construído como parte do processo de desenvolvimento, nem antes nem depois - ainda que o ambiente político da Alemanha, e da Europa de modo geral, não tenha logrado naquele momento reconciliar o emergente capitalismo com a sociedade civil e a democracia, dando origem às décadas de perturbação do início do século XX (Berman, 2006).

Já na reconstrução da Alemanha do pós-guerra, o experimento que coloca em prática a doutrina social-cristã da "economia social de mercado" endossada por Konrad Adenauer e sua União Democrata-Cristã (Kerstenetzky e Kerstenetzky, 2014b) se fez com acomodação exitosa entre forças de mercado e democracia, com raízes na então já longa tradição corporativista, produzindo crescimento pujante ao menos até os anos 1980. Um elevado grau de coordenação entre questões econômicas e sociais assegurou proteção em relação a riscos para bancos, indústria e trabalho, fazendo parte desta coordenação um Estado de bem-estar financiado por contribuições. Este garante aos trabalhadores reposição de rendimentos, nas então habituais circunstâncias de risco das sociedades industriais capitalistas. Sob o arranjo de "parceria social" de estilo alemão, sindicatos de trabalhadores e empregadores 
barganham salários e emprego de forma autônoma, com consequências em termos de crescimento, inflação e desemprego, enquanto aos sindicatos é garantida voz na gestão de firmas individuais e na administração do sistema de seguridade social (Streeck e Hassel, 2004).

A relação entre desenvolvimento e democracia também lança luz sobre a trajetória de países emergentes, como a Coreia e o Brasil (Kerstenetzky, 2014; Kerstenetzky, 2012), que transitaram de regimes autoritários a democráticos. A história coreana tem início na rápida acumulação de capital entre os anos 1960 e 1980, sob a condução de um governo autoritário (Woo-Cumings, 1999). Visando ao rápido crescimento industrial, o Estado "parteiro" fomentou grupos industriais e estabeleceu com eles uma relação próxima, com canalização de recursos escassos em troca de compromisso de desempenho econômico e absorção de tecnologia (Amsden, 1989). O rápido crescimento econômico que elevou significativamente a renda agregada (também auxiliado por investimentos prévios em educação e por uma reforma agrária) se fez acompanhar por um governo autoritário, forte repressão política, atividade sindical fraca e bem-estar social deficiente. O governo militar assegurou benefícios sociais para segmentos selecionados da população (professores, soldados e funcionários públicos), mas coube aos empresários prover obrigatoriamente benefícios aos seus empregados (Sook, 2004) e às famílias (especialmente às mulheres) cuidar dos inativos e desempregados (Gough, 2004).

O modelo de contenção de pressões acabou por romper-se nos anos 1980. A insatisfação crescente com o governo trouxe mobilização política e democratização e abriu caminho para o progresso em bem-estar social (Sook, 2004; Evans e Heller, 2015), que se intensificou especialmente após a crise asiática, no final dos anos 1990. Apesar da acumulação de capital e do crescimento rápido no período de catch up, foi com a democracia e uma nova orientação na direção de um bem-estar universal que a proteção social se difundiu, ao mesmo tempo que a economia seguiu crescendo (Evans e Heller, 2015). O caso brasileiro, de sucesso bem mais comedido, traça, contudo, percurso semelhante, com período de crescimento acelerado sob regime autoritário seguido, com um intervalo de quase duas décadas, pela combinação recente de democracia, aumento de bem-estar social e crescimento moderado (Kerstenetzky, 2012, 2014).

Se o Estado de bem-estar social foi um fator crítico para assegurar o bem-estar na era industrial, e assim legitimar a mudança econômica, 
o mesmo parece se aplicar às economias do conhecimento das sociedades pós-industriais contemporâneas. Neste novo ambiente, os processos econômicos, em combinação com mudanças demográficas e sociais, acrescentaram outros riscos sociais às incertezas dos ciclos de vida e econômico: conexões precárias de mercado de trabalho, composições familiares heterogêneas e envelhecimento das populações (Esping-Andersen, 1999, 2009). Riscos sociais de nível elevado representaram um provável impulso para a expansão do Estado de bemestar nas economias centrais nos anos 1980 e 1990 e para sua difusão a regiões como o Sudeste Asiático e a América Latina nos anos 2000, onde ele se combinou com o processo de democratização (Castles et al., 2010; Haggard e Kaufman, 2008; Kerstenetzky, 2012).

Observou-se ainda que o Estado de bem-estar afeta diretamente a produção de riqueza, uma função crítica em face das demandas e requisitos da economia do conhecimento. De fato, estudos sobre experiências de desenvolvimento econômico identificaram funções legitimadoras e "produtivistas" do bem-estar social, como a negociação de esforços produtivos em troca de direitos sociais (Chang e Kozul-Wright, 1994; Kaspersen e Schmidt-Hansen, 2006) e estímulo adicional à inovação via garantia de segurança econômica e políticas de educação e formação de longa duração (Kangas e Palme, 2005; Boyer, 2008). Tais ações, que são a marca registrada do modelo socioeconômico escandinavo, são examinadas no estudo do caso dinamarquês apresentado mais adiante neste artigo, depois de abordarmos mais uma perspectiva fundamental na próxima seção.

\section{RESSIGNIFICANDO O DESENVOLVIMENTO E O ESTADO DESENVOLVIMENTISTA}

A multiplicidade de experiências nacionais, sejam elas variadamente exitosas, sejam fracassadas, suscita uma reflexão normativa a respeito do que se deve propriamente entender por desenvolvimento. De um lado, observando o que em termos econômicos geralmente se compreende como experiência bem-sucedida, o catch up dos tigres asiáticos, poder-se-ia argumentar, como alguns fizeram, que tais países alcançariam ainda mais sob democracias no lugar de conexões exclusivas entre a burocracia estatal e as elites. Por outro lado, experimentos de crescimento econômico com resultados pobres em termos de bem-estar, de "opulência sem propósito" (Drèze e Sen, 2002), como o Brasil dos anos 1970, dificilmente se sustentam como casos de desenvolvimento, sem 
qualificação adicional: houve crescimento acelerado e redução da pobreza de renda, mas aumento significativo da já elevada desigualdade e insuficiente evolução de indicadores sociais como mortalidade infantil, analfabetismo e acesso a serviços básicos. Da mesma forma, a avaliação de trajetórias e realizações de diferentes países desenvolvidos pode estimular comparações de sucesso relativo, em aspectos que vão além dos rendimentos per capita, os quais, na realidade, os diferenciam pouco. Um exemplo são os diferentes graus de desigualdade econômica, resultantes, em parte, de configurações distintas de Estados de bem-estar social, que aparecem na comparação da Dinamarca universalista (Gini de 0,24 em 2011) com a Alemanha corporativista $(0,29)$ ou dos EUA $(0,37)$ com países da Europa continental $(0,29)$. Em termos gerais, a reflexão normativa é estimulada pela crescente insatisfação com a equiparação de desenvolvimento com acumulação de capital e crescimento do produto/renda per capita, e pela reação a ela, sob a forma de crescente fixação finalista em realizações, estados e atividades humanas. A assim denominada abordagem das capacitações se destaca por proporcionar referencial candidato a atender tais inquietações (Sen, 1983) ${ }^{3}$.

A abordagem das capacitações recupera a ideia original de desenvolvimento como promoção de bem-estar e formaliza esta noção como expansão de reais liberdades ou capacidades que pessoas e grupos possuem para viver vidas que considerem significativas. Argumenta que estas não são redutíveis a crescimento do produto per capita. Liberdades reais incluiriam aspectos de oportunidade e de agência: requerem condições sociais que permitam às pessoas tomar decisões autônomas a respeito de planos de vida, inclusive por meio da participação em decisões coletivas que afetam seus planos, e seguir o planejado. Se, como sugerido, desenvolvimento se traduz em liberdade (Sen, 1999), políticas de desenvolvimento deveriam tratar de criar e sustentar suas precondições, e o produto per capita não seria o único fator importante.

De fato, na perspectiva da abordagem das capacitações, a substituição dos objetivos genuínos do desenvolvimento por algo que deveria permanecer apenas como um dos meios para alcançá-los tem consequências negativas. Liberdades reais não estão à venda nos mercados e podem estar ausentes enquanto o produto cresce e as políticas estão fixadas no seu crescimento. O estado de saúde de uma população é mais bem servido pelo cuidado dispensado à saúde do que através de políticas de crescimento econômico (Sen, 1989; Drèze e Sen, 2002). A liberda- 
de de não passar fome se refere mais a titularidades - tanto de propriedade como de troca, e de provisões sociais e políticas como proteção social, direitos, democracia - do que a poder de compra (Sen, 1983, 1999). De maneira geral, proteção social, direitos e democracia seriam centrais na promoção de capacitações pouco relacionadas aos rendimentos, como saúde, educação, igualdade social, autorrespeito ou liberdade em relação a "assédio social" (Sen, 1983). Portanto, desenvolvimento nessa visão seria mais apropriadamente descrito como mudança social, processo pelo qual o domínio das circunstâncias e da sorte sobre os indivíduos é substituído pelo domínio dos indivíduos sobre circunstâncias e sorte (Marx apud Sen, 1983).

Segue-se então um deslocamento da atenção dos mercados em direção à política, na medida em que a mudança social dependeria de decisões coletivas (Sen, 1983). Outra consequência é o papel central atribuído à escolha democrática sobre itens e prioridades no interior do conjunto das capacitações, o que decorre do reconhecimento de sua multidimensionalidade e da importância conferida à dimensão da agência. Mas, ainda assim, não seria o crescimento do produto favorável à expansão das capacitações?

Alguns estudos empíricos analisaram a relação entre crescimento econômico e bem-estar (Drèze e Sen, 2002; Stewart et al., 2011) e concluíram que crescimento sem promoção prévia de capacitações (basicamente, saúde e educação) não parece sustentar-se ou levar à expansão posterior de capacitações (Stewart et al., 2011); e que políticas que procuram impulsionar o crescimento não são suscetíveis de levar a crescimento sustentado a não ser que incrementos nas capacitações também sejam diretamente perseguidos. Tais resultados são compatíveis com recentes teorias do crescimento, que enfatizam educação e investimentos em tecnologia como fatores reproduzíveis por meio dos quais o crescimento presente pode se converter em crescimento futuro. Outros estudos, relatados em Stewart et al. (2011), apontam em direção semelhante, ao observar que certo nível de educação deve ser atingido antes que a economia se liberte da armadilha de baixa renda, após o que o crescimento econômico ampliará capacitações. Dentre os impactos mensurados de capacitações sobre o crescimento estão os efeitos de aumento de produtividade relacionados à saúde e educação e os de despesas em educação e saúde sobre o investimento privado. Investimentos precoces em educação na Coreia ilustram o caso (Chang e Kozul-Wright, 1994; Evans e Heller, 2015). Outras referências são os in- 
vestimentos em educação realizados por países de desenvolvimento retardatário, como a Alemanha e os países escandinavos (Chang, 2002; Kangas e Palme, 2005). Porém, como abordagem mais geral, a abordagem das capacitações elabora uma estrutura na qual as funções instrumentais não esgotariam o valor da educação, que é vista como objetivo de desenvolvimento em si, para além de sua utilidade para outros propósitos (por exemplo, crescimento sustentado). O mesmo valeria para a democracia. Esse modo de ver decorre da dupla natureza da liberdade real, como oportunidade e como agência.

Na realidade, quando se trata da influência da renda agregada sobre as capacitações, os resultados são mistos. Há suporte empírico para a noção de que, por exemplo, reduções na taxa de mortalidade e incrementos na expectativa de vida tenham sido induzidos por melhorias tecnológicas e, indiretamente, por aumentos na renda agregada (Stewart et al., 2011). Mas o registro histórico também documenta casos em que aumentos nas capacitações são consistentes com uma abordagem mais direta, não mediada pela renda. Há forte evidência, por exemplo, de que, se a interação entre saúde básica e resultados em educação é forte, ambos estão frouxamente relacionados com a renda (Drèze e Sen, 2002).

Casos conhecidos de desenvolvimento não mediado por crescimento econômico contaram com a ação do Estado. Isso é sugerido, por exemplo, pelo notório experimento de desenvolvimento do densamente povoado estado indiano de Kerala (que conta com uma população de 32 milhões de pessoas). Na medida em que apoiou a mobilização social para a promoção de capacitações básicas, a ação do Estado foi capaz de dar início a um ciclo de realizações por meio do qual outras liberdades se fortaleceram, entre elas a liberdade de participar da mudança social.

Em Kerala, a ação pública (Drèze e Sen, 2002), empreendida por atores do Estado em conjunto com organizações políticas e sociais, deu início em 1950 a um processo de redistribuição de titularidades e realocação de prioridades que, nas décadas seguintes, sob a liderança de governos de esquerda (aglutinados em torno do Partido Comunista da Índia - Marxista), envolveu reforma agrária, alfabetização e matrícula escolar em massa, gerando uma cidadania educada e politicamente ativa que seguiu demandando oportunidades sociais e empoderamento. A viabilidade prática desse processo não mediado por crescimento foi garantida pela natureza intensiva em trabalho da provisão pública de educação primária e de cuidados básicos de saúde, em uma economia 
de baixos salários, e por complementaridades entre resultados educacionais e status de saúde (Drèze e Sen, 2002).

Outro ingrediente, principalmente na segunda fase da experiência desenvolvimentista nos anos 1990, foi a ampla mobilização social, como ilustram a campanha de alfabetização em massa de 1991 e, sobretudo, o amplo processo de planejamento participativo descentralizado iniciado em 1996 (Isaac e Franke, 2002). Nesse experimento, foi instrumental uma mudança doutrinária no âmbito do $\mathrm{PCI}(\mathrm{M})$, que passa a considerar a descentralização democrática e a participação popular direta na concepção, planejamento, gestão e controle de políticas públicas como ação socialmente transformadora.

Superando a Índia em muitos indicadores sociais e apresentando realizações comparáveis à Coreia em expectativa de vida, mortalidade infantil e alfabetização, Kerala alcançou elevado desenvolvimento social apesar do diminuto produto per capita. O caso ilustra a força e a eficácia de fatores políticos - uma democracia consolidada, um partido governante compromissado e responsivo, e intensa mobilização política e social de organizações populares - no redirecionamento das prioridades do desenvolvimento. Em um bom número de interpretações da experiência de Kerala, a participação e o franco empoderamento dos desprivilegiados são considerados objetivos finais do processo de desenvolvimento (Isaac e Heller, 2003; Isaac e Franke, 2002; Véron, 2001) - ofuscando os resultados econômicos.

Quando considerados os casos de desenvolvimento mediado por crescimento, mais uma vez, a provisão pública de oportunidades para capacitação, não o crescimento em si, parece ter feito a diferença (Drèze e Sen, 2002; Kenworthy, 2010). Redistribuindo renda para financiar a provisão de oportunidades que afetam o bem-estar das pessoas e suas perspectivas de vida, o Estado de bem-estar foi a forma de Estado que prevaleceu: ao apoiar o progresso econômico, contribuiu para aumentar a disponibilidade de recursos para a provisão pública ampliada; com direitos civis e políticos garantidos, em um ambiente democrático, contribuiu para aprofundar a democracia pela institucionalização de mecanismos de negociação, coordenação e deliberação entre grupos da sociedade; ao mitigar desequilíbrios sociais, contribuiu para aumentar o valor dos direitos para os cidadãos. De fato, Estados de bem-estar reduzem a pobreza e as desigualdades dos rendimentos de mercado em toda parte, em especial aqueles mais robustos localiza- 
dos em países europeus (OECD, 2008). Dentre estes últimos, os mais universalistas, do norte da Europa, são os que promovem os mais baixos graus de pobreza e desigualdade de renda pós-fisco e desigualdade de oportunidades sociais (Checchi et al., 2008).

Com o auxílio da abordagem das capacitações e, portanto, sob uma perspectiva mais ampla não confinada à renda, o Estado de bem-estar aparece como um meio geral de alcançar oportunidades para múltiplas capacitações, relacionadas seja ao bem-estar, seja à agência dos cidadãos. Na próxima seção, detalhamos esses efeitos amplos na experiência dinamarquesa, que abriga um dos mais robustos Estados sociais da contemporaneidade ao lado de uma pujante economia de mercado. Capacitações traduziram-se em cobertura de riscos sociais e provisão de oportunidades sociais, extensiva e generosa, e um tipo peculiar de democracia, participativa e altamente descentralizada.

\section{UM ESTADO DESENVOLVIMENTISTA DE COMPARTILHAMENTO DE PODER E CRESCIMENTO: DINAMARCA}

Três características têm atraído a atenção dos estudiosos do modelo dinamarquês de desenvolvimento: os padrões elevados de garantia de bem-estar e democracia; o elevado nível de bem-estar apoiado em igualmente elevadas taxas de atividade econômica; a atividade econômica e a promoção de capacitações baseadas em estreita conexão entre Estado e organizações / associações da sociedade civil. A evidência inclui altos índices de satisfação com a democracia (Demokratiudvalget, 2004 apud Kristensen, 2011) e de emprego total, feminino e de idosos (OECD, 2009); igualdade social e econômica e pobreza pós-fisco reduzida (Checchi et al., 2009; OECD, 2009); satisfação no trabalho (European Commission, 2004); e conciliação da vida familiar com o trabalho (European Commission, 2004).

A história dessas interações virtuosas entre mercados competitivos, sociedade civil ativa e Estado forte começa no final do século XIX, quando teve início o apoio oficial a associações voluntárias, bem como inovações institucionais e de políticas públicas, após um histórico de intensos conflitos sociais e políticos e elevadas desigualdades (Obinger et al., 2010; Atkinson e Sogaard, 2013). Explicações sociocêntricas da origem desses arranjos no século XIX contestam explicações estadocêntricas e vice-versa. Em todo caso, foi nessa época que surgiu e se institucionalizou o estilo de parceria social dinamarquesa, envol- 
vendo densos grupos de interesse e o Estado em uma longa tradição de elaboração de políticas por meio de consensos. Foi também nesse momento que foram fincadas as raízes da prática de transformação econômica negociada, incluindo troca de restrição salarial por direitos sociais. Outros ingredientes a reforçar o experimento inicial foram a intensa mobilização política e os governos social-democratas, que duraram cerca de cinquenta anos ao longo do século XX até os anos 1970.

Após a Segunda Guerra Mundial, sob liderança social-democrata, tomaram forma os contornos maduros do Estado de bem-estar dinamarquês que, após flertar brevemente no entreguerras com princípios de seguridade baseada em contribuições de tipo alemão, optou pelo universalismo, combinando elevados níveis de adequação dos benefícios com uma visão abrangente de risco e proteção social (Obinger et al., 2010; Esping-Andersen, 1990). Foi concebida uma variedade de benefícios e serviços de qualidade, financiados por impostos gerais, para proteger a totalidade dos cidadãos (não apenas os trabalhadores) das vicissitudes do ciclo da vida e das incertezas econômicas e infortúnios intergeracionais.

Nos "anos dourados" do pós-guerra, o Estado de bem-estar veio a ser também instrumental para o alcance de altos patamares de emprego e atividade econômica. Foi importante fonte de empregos (em torno de $30 \%$, em sua maior parte feminino) e facilitou a participação econômica feminina, ao introduzir creches universais e políticas de família, como as licenças-maternidade e paternidade remuneradas e as prestações familiares. O modelo de família de duas fontes de rendimentos (dual-earner families) foi fortemente encorajado, entre outras medidas com a introdução do imposto de renda individualizado, o que provou mais tarde ser um potente escudo contra a pobreza infantil e um futuro pobre, colocando a Dinamarca em posição privilegiada nesse quesito entre os países da OECD. O investimento público em educação na primeira infância também se mostrou um equalizador de perspectivas de vida. Finalmente, a criação de um sistema de emprego público, outra inovação do período, veio a revelar-se estratégica nas décadas seguintes.

Quando sobreveio a crise dos anos 1970 e tornou-se clara a necessidade de mudanças estruturais na economia e na sociedade, os dinamarqueses, ao mesmo tempo em que se mantiveram fiéis ao estilo consensual de elaboração de políticas, liberalizaram suas políticas econômicas e 
expandiram e recalibraram suas políticas sociais, disto obtendo benefícios. De fato, embora tenha elevado continuamente a despesa social de forma a ultrapassar a metade da despesa pública e um terço do PIB nos anos 2000, a Dinamarca beneficiou-se da economia do conhecimento e da globalização (Kristensen, 2011), atingindo os melhores resultados no índice de competitividade do Fórum Econômico Mundial e de PIB per capita nos anos 2000 (ibidem), além de níveis máximos de participação da força de trabalho e baixo desemprego já nos anos 1990 (Kenworthy, 2004).

Duas inovações associadas ao alto grau de autonomia nacional na formulação de políticas, raro em um contexto de liberalização econômica e integração europeia, parecem responsáveis por alçar a Dinamarca à dianteira da economia do conhecimento com prosperidade social.

A primeira é a "flexiseguridade" (flexicurity), uma combinação de mercado de trabalho flexível e benefícios de bem-estar generosos com políticas de mercado de trabalho ativas. Ao acomodar os anseios de mercados competitivos por flexibilidade com os de trabalhadores por segurança econômica e prosperidade, estas políticas proporcionam treinamento e retreinamento de longo prazo, adicionando à flexibilidade do trabalho perspectivas de maior qualificação, melhores postos de trabalho e aprendizado ao longo da vida.

A outra é o suporte público a investimentos privados em inovação. Este combina coordenação e financiamento com despesas do Estado de bem-estar: educação pública universal, treinamento e retreinamento da força de trabalho, aprendizado ao longo da vida e educação na primeira infância, promotora de habilidades cognitivas, em combinação com benefícios monetários que contribuem para garantir a atividade contínua da população (Huo e Stephens, 2015). Estas políticas interagiram positivamente com o chamado "aprendizado discricionário", forma de organização do trabalho que enfatiza a autonomia máxima do trabalhador, disseminado pela maioria dos empregos dinamarqueses (ibidem), para o que contribuiu a elevada densidade sindical típica do Estado de bem-estar nórdico (Esser e Olsen, 2012). O aprendizado discricionário, muito valorizado nos sistemas de inovação em rede (networked innovation systems), em que há alto grau de cooperação entre firmas, empregadores, trabalhadores e localidades (Kristensen, 2011), acarretou elevado nível de satisfação no trabalho entre os trabalhadores dinamarqueses (European Commission, 2004). 
À medida que o Estado desempenhava novas funções - de fato, atualizando o compartilhamento e atendimento a riscos sob as novas circunstâncias -, mais de seu funcionamento interno ia se tornando aparente.

As burocracias nórdicas são conhecidas por sua qualidade, mas uma característica adicional é terem florescido dentro da tradição democrática de negociação e parceria com os principais interesses organizados. Na variedade de comissões e comitês de consulta, preparação de legislação e implementação de políticas, em conjunto com o sistema político, burocratas dinamarqueses praticam sua relativa autonomia ao mesmo tempo em que dividem o espaço político com atores sociais centrais (Kaspersen e Schmidt-Hansen, 2006). Estes, por sua vez, acabam se "cultivando" em deliberação pública quanto ao bem-estar, à organização de firmas e temas econômicos e sociais relevantes (Boyer, 2008) - um processo que, embora não elimine conflitos, minimiza impasses e a necessidade de intervenção governamental de cima para baixo. Mais recentemente, a partilha do poder se estendeu a uma variedade de associações e agendas de cidadãos e tornou-se menos centralizada, reforçando ainda mais o componente direto da democracia dinamarquesa (Kristensen, 2011; Boyer, 2008). Este tipo peculiar de estatização deve constituir uma das explicações para o reduzido grau de insatisfação dos dinamarqueses com a globalização (Kristensen, 2011), ao facilitar a negociação de direitos sociais por competitividade, e desse modo tornar compartilhados os frutos do crescimento. Uma ilustração é a reforma do mercado de trabalho de 1994 que introduziu a já mencionada "flexiseguridade" (Kaspersen e Schmidt-Hansen, 2006).

Várias análises observam que o investimento centrado nas pessoas e ao longo de suas vidas priorizado pelos dinamarqueses não significa necessariamente que sua orientação igualitária se traduza em igualdade aqui e agora: o fato de uma porção de pessoas se mover do emprego ao desemprego e de volta ao emprego ou educação e treinamento, mesmo com segurança econômica, pode em alguns momentos comprometer esse objetivo. Talvez onde com mais força essa orientação se encontre resguardada seja em termos da igualdade de chances de vida e proteção (Esping-Andersen, 1999), portanto igualdade ao longo da vida, especialmente à medida que o país embarca na economia inovativa e experimental, um ambiente de mudanças e incerteza (Kristensen, 2011).

Por estar o modelo socioeconômico enraizado em um etos febrilmente mercantil, resta saber se será capaz de resistir às desigualdades cres- 
centes e ameaças à solidariedade social que assombram as economias do conhecimento. Até o momento o processo foi em sua maior parte negociado e, em consequência, o alinhamento de meios e fins do desenvolvimento, a alma do regime dinamarquês, segue garantindo uma economia política que lhe dá suporte.

\section{OBSERVAÇÕES FINAIS}

Conforme a ideia de desenvolvimento viaja no tempo, modifica-se a compreensão da ação do Estado. Se por um longo tempo essa ideia esteve capturada pela noção de transformação econômica, cuja promoção era conferida a um Estado administrador-planejador, hoje é geralmente reconhecido que a dimensão política é central para controlar a economia política do desenvolvimento: para quem irão os frutos? Mas, não apenas "como fazer?" e, mais radicalmente, "o que fazer?" são questões que já se consideram da alçada da cidadania, não exclusivamente de burocratas insulados ou articulados com elites.

Ademais, a análise do desenvolvimento não se pode furtar a continuamente ressignificar as experiências passadas à medida que olha para os novos desafios. Já não é mais possível reduzir a experiência europeia do pós-guerra à simples industrialização sem compreender o quanto se negociou e condicionou esse processo ao consenso entre os atores sociais centrais quanto à repartição dos frutos e participação no poder: não apenas garantias de bem-estar foram construídas como também mecanismos de negociação e deliberação sobre políticas públicas tornaram-se institucionalizados.

Em face de novos significados, dificilmente alguma experiência estará solidamente estabelecida como um padrão a ser imitado. De fato, alguns dos assim chamados países desenvolvidos podem parecer menos desenvolvidos, quando, por exemplo, dão livre curso a crescentes desigualdades de bem-estar e, dentre os menos desenvolvidos, alguns estarão aptos a ensinar uma ou duas lições, quando, por exemplo, inovam em experimentos participativos.

Em termos abstratos, o conceito de desenvolvimento proposto por Sen, ao proporcionar uma referência para se pensar a noção genérica de bem-estar, procura capturar a plasticidade de significados. O desenvolvimento é expansão das possibilidades de realização humanas, e, portanto, libertação das constrições sociais que a tolhem. O conceito, porém, não lista as realizações nem especifica as suas condições de 
possibilidade. Seu maior atrativo é justamente delegar a fixação de conteúdos e condições à deliberação democrática - implicitamente acomodando a natureza plural e até certo ponto incomensurável do "bem", isto é, os propósitos do desenvolvimento (p.ex., consumo, participação, equidade, sustentabilidade).

A deliberação democrática, por sua vez, encontra justificação direta na liberdade de agência humana (possibilidade de participação em decisões que promovem mudança social) que, ao lado da liberdade substantiva para a realização de demais potencialidades humanas, é central nessa perspectiva. Democracia, portanto, não seria exclusivamente buscada por sua influência sobre efetividade e legitimidade de experimentos desenvolvimentistas, mas também por ser expressiva da condição de agentes livres dos cidadãos e, por isso, componente integral do desenvolvimento.

Uma consequência evidente é que o Estado desenvolvimentista deverá não apenas se valer de, como encorajar, mecanismos de escolha democrática. O lugar do Estado segue justificado, na medida em que a categoria interesse público faz sentido no discurso sobre o desenvolvimento e a mais ampla participação política é mecanismo adequado de decisão quanto ao seu conteúdo.

Quando nos voltamos para as experiências nacionais, a forma de Estado que nas décadas do pós-guerra pareceu mais efetivamente conduzir ao desenvolvimento de capacitações e agência foi o Estado de bemestar social. Em princípio isso teria ocorrido por sua capacidade de neutralizar o "domínio das circunstâncias e da sorte" sobre as liberdades reais dos indivíduos e de tornar a transformação econômica mais legítima e efetiva como meio para a mudança social.

Na realidade, democracias tornaram o Estado do bem-estar mais responsivo. Quando associado a regimes democráticos, o Estado de bemestar social pode proporcionar o que a maioria dos eleitorados escolheu como as prioridades do desenvolvimento. Este potencial se verificou não só em experimentos produtivistas como o alemão e o coreano como também em casos marcados por deliberado não produtivismo como o de Kerala, que, não obstante, podem ser igualmente considerados como forma de Estado de bem-estar porque envolveram redistribuição, provisão de bens públicos e mobilização política. Reciprocamente, Estados de bem-estar podem contribuir para aprofundar democracias: intervenções de promoção de igualdade aumentam o valor 
das liberdades políticas para os menos favorecidos, e mecanismos de negociação e participação tornam-nas mais diretas e representativas. Quando isto ocorre, como na experiência dinamarquesa, Estados de bem-estar democráticos revelam graus significativos de flexibilidade para lidar com circunstâncias que representem novos riscos sociais, como a globalização, o envelhecimento das populações e mudanças nas estruturas familiares.

Estados de bem-estar social e democracias, contudo, existem sob diferentes formas e graus de sucesso em termos de desenvolvimento como liberdade. Alguns, por exemplo, reduzem pouco as desigualdades de renda e de oportunidades e a pobreza (OECD, 2008; Acemoglu et al., 2013). Desse modo, são questões de interesse, além do estudo da diversidade institucional e de economias políticas de Estados do bem-estar e democracias, os diferentes elementos que compõem o conjunto de capacitações objeto da escolha social. No estudo desses elementos, é importante identificar tensões e complementaridades entre eles, por exemplo, participação política e representação; participação e igualdade; padrões de vida crescentes, desigualdades geradas pelo mercado e apoio político à redistribuição; evolução de padrões de vida e sustentabilidade ambiental. Ademais, do ponto de vista político, a identificação de coalizões desenvolvimentistas, bem como de mobilização social e ação pública em sentido amplo, parece central. Os dois casos de maior sucesso relativo aqui destacados contaram com governos duradouramente dominados por coalizões de esquerda e ampla e institucionalizada mobilização social e descentralização. Os partidos de esquerda que lideraram essas coalizões vocalizaram concepções igualitaristas (igualdade de condições) e participativistas (participação direta e localismo) de desenvolvimento.

Cabe ainda assinalar que a escolha social de Kerala, de realizações várias sem crescimento, já provoca tensões e reacomodações no modelo para atender a novas exigências de bem-estar que, contudo, conflitam com equilíbrios sociais previamente alcançados. Ademais, a ênfase em uma abordagem classista não teria evitado clivagens societárias por casta/religião/gênero, mesmo que no confronto com o restante da Índia estas tenham sido minimizadas. A escolha dinamarquesa de bem-estar com crescimento baseado em inovações está aumentando a porção da renda apropriada pelo um por cento mais rico (EspingAndersen, 2013). Além disso, a inserção diferenciada dos imigrantes atraídos pelo sucesso do modelo ameaça o seu universalismo. Como se 
desdobrarão essas tensões? Há ainda o problema da escala envolvendo as histórias de sucesso relativo de Kerala e Dinamarca: seriam suas realizações possíveis em países como a Nigéria e o Brasil, onde a ação social concertada, em virtude do mero tamanho, pode mostrar-se mais difícil de alcançar? Ainda que neste último caso, a descentralização seja uma avenida a explorar, não há como negar que estas questões, essencialmente empíricas, deverão despertar interesse.

Em todo caso, parece inevitável que estudos futuros se voltem para a diferenciação de formas de democracia e descentralização, e configurações alternativas de Estado de bem-estar social, no esforço de compreender as dinâmicas por vezes paradoxais da promoção do desenvolvimento.

(Recebido para publicação em março de 2014)

(Reapresentado em março de 2015)

(Aprovado para publicação em abril de 2015) 


\section{NOTAS}

1. O argumento de Krueger (1990) consiste em atribuir falhas de governo ao fato de servidores públicos não serem desprovidos de interesses, serem sim uma mistura de pessoas sob pressões e interesses em competição, com rent seekers e interessados em políticas de governo organizados para pressionar por aumento de benefícios ou redução de perdas decorrentes de políticas de governo.

2. Nas palavras de Johnson (1982), resumidas em Johnson (1999:37-39), o Estado desenvolvimentista tem por essência a prioridade dada ao desenvolvimento, de forma que sua atuação ultrapassa os marcos de um Estado regulatório, que teria atuação restrita a formas e procedimentos, ou seja, regras de competição. Em sua atuação substantiva, o problema fundamental se refere ao relacionamento com os negócios privados, e seus elementos centrais são uma burocracia estatal de elite, pouco dispendiosa e formada a partir dos melhores talentos disponíveis, um sistema político no qual esta burocracia possa tomar iniciativas e operar eficientemente, o aperfeiçoamento de métodos de intervenção estatal adequados ao funcionamento do mercado, e a agência de controle de política industrial que combine planejamento, energia, produção doméstica, comércio internacional e parte das finanças referentes à oferta de capital e política fiscal.

3. Por razões de espaço e da sequência de construção do argumento, não abordamos neste artigo a proposição de sustentabilidade do desenvolvimento. Para uma análise da abordagem das capacitações de Sen em suas relações com o conceito de desenvolvimento sustentável ver o número especial do Journal of Human Development and Capabilities sobre o tema (vol. 14, no 1,2013 ). 


\section{REFERÊNCIAS BIBLIOGRÁFICAS}

ACEMOGLU, Daron et al. (2013), "Democracy, Redistribution and Inequality". Working Paper 13-24, Massachusetts Institute of Technology, Department of Economics.

AGARWALA, Amar H.; SINGH, Sampat P. (eds.). (1958), The Economics of Underdevelopment. A Series of Articles and Papers. Bombay/New York, Oxford University Press.

AMSDEN, Alice H. (1989), Asia's Next Giant: South Korea and Late Industrialization. New York, Oxford University Press.

ATKINSON, Anthony B.; SOGAARD, Jakob E. (2013), “The Long-run History of Income Inequality in Denmark: Top Incomes from 1870 to 2010". EPRU Working Paper Series, 2013-01.

BARDHAN, Pranab. (2005), “Institutions Matter, but which Ones?”. Economics of Transition, vol. 13, no 3, pp. 499-532.

BERMAN, Sheri. (2006), The Primacy of Politics: Social Democracy and the Making of Europe's Twentieth Century. New York, Cambridge University Press.

BIELSCHOWSKY, Ricardo. (2009), “Sesenta Años de la Cepal: Estructuralismo y Neoestructuralismo". Revista CEPAL, vol. 97, pp. 173-194.

BOYER, Robert. (2008), “Democracy and Social Democracy Facing Contemporary Capitalisms: A ‘Régulationist' Approach". Working Paper 2008-36, Paris, Paris-Jourdan Sciences Economiques, Laboratoire D’Economie Appliquée (Inra).

CASTLES, Francis G. et al. (eds.). (2010), The Oxford Handbook of the Welfare State. Oxford, Oxford University Press.

CHANG, Ha-Joon. (2002), Kicking away the Ladder: Development Strategy in Historical Perspective. London, Anthem Press.

CHANG, Ha-Joon; KOZUL-WRIGHT, Richard. (1994), “Organising Development: Comparing the National Systems of Entrepreneurship in Sweden and Korea". The Journal of Development Studies, vol. 30, no 3, pp. 859-891.

CHECCHI, Daniele et al. (2008), "Income Inequality and Opportunity Inequality in Europe". Rivista di Politica Economica, nos IX-X, pp. 263-292.

DEMOKRATIUDVALGET. (2004), Democrati i Norden. Copenhagen, Nordisk Ministerrad.

DRÈZE, Jean; SEN, Amartya. (2002), India: Development and Participation. 2a ed. New York, Oxford University Press.

ESPING-ANDERSEN, Gosta. (1990), The Three Worlds of Welfare Capitalism. Princeton, Princeton University Press.

. (1999), Social Foundations of Postindustrial Economies. Oxford University Press, USA.

. (2009), Incomplete Revolution: Adapting Welfare States to Women's New Roles. Cambridge, UK; Malden, MA, Polity.

. (2013), Equality with a Happy Bourgeoisie. The Social Democratic Road to Equality. Disponível em http://dcpis.upf.edu/ gosta-esping-andersen/materials/equality. pdf. Acesso em fevereiro de 2014. 


\section{O Estado (de Bem-Estar Social) como Ator do Desenvolvimento}

ESSER, Ingrid; OLSEN, Karen M. (2012), “Perceived Job Quality: Autonomy and Job Security within a Multi-Level Framework". European Sociological Review, vol. 28, no 4, pp. 443-454.

EUROPEAN COMMISSION. (2004), Industrial Relations in Europe. Brussels, DirectorateGeneral for Employment and Social Affairs.

EVANS, Peter. (1995), Embedded Autonomy: States and Industrial Transformation. Princeton, Princeton University Press.

; HELLER, Patrick. (2015), "Human Development State Transformation and the Politics of Developmental State", in S. Leibfried et al. (eds.), The Oxford Handbook of Transformations of the State. Oxford, Oxford University Press, pp. 691-713.

GERSCHENKRON, Alexander. (1962), Economic Backwardness in Historical Perspective. Cambridge, Belknap Press of Harvard University Press.

GOLDMAN, Michael. (2005), Imperial Nature: The World Bank and Struggles for Social Justice in the Age of Globalization. New Haven/London, Yale University Press.

GOUGH, Ian et al. (2004), Insecurity and Welfare Regimes in Asia, Africa and Latin America: Social Policy in Development Contexts. Cambridge/New York, Cambridge University Press.

HAGGARD, Stephan; KAUFMAN, Robert K. (2008), Development, Democracy, and Welfare States: Latin America, East Asia, and Eastern Europe. Princeton, Princeton University Press.

HECKSCHER, Eli. (1935), Mercantilism. Oxford, Routledge.

HERRICK, Bruce; KINDLEBERGER, Charles H. (1983), Economic Development. New York, McGraw-Hill College.

HIRSCHMAN, Albert O. (1958), Strategy of Economic Development. New Haven, Yale University Press.

HUO, Jingjing; STEPHENS, John D. (2015), “From Industrial Corporatism to the Social Investment State", in S. Leibfried et al. (eds.), The Oxford Handbook of Transformations of the State. Oxford, Oxford University Press, pp. 410-425.

ISAAC, Thomas; FRANKE, Richard W. (2002), Local Democracy and Development: The Kerala People's Campaign for Decentralized Planning. Lanham, Md., Rowman \& Littlefield Publishers.

ISAAC, Thomas; HELLER, Patrick. (2003), “Decentralization, Democracy and Development: The People's Campaign for Decentralized Planning in Kerala", in A. Fung e E. O. Wright (eds.), Deepening Democracy: Institutional Innovations in Empowered Participatory Governance. London/New York, Verso.

JOHNSON, Chalmers. (1982), MITI and the Japanese Miracle: The Growth of Industrial Policy, 1925-1975. Stanford, Stanford University Press.

. (1999), "The Developmental State: Odissey of a Concept", in M. Woo-Cumings (ed.), The Developmental State. Ithaca, Cornell University Press.

JUDT, Tony. (2005), Postwar: A History of Europe since 1945. New York, Penguin Press.

KANGAS, Olli; PALME, Joakim (eds.) (2005), Social Policy and Economic Development in the Nordic Countries. New York, Palgrave Macmillan. 
KASPERSEN, Lars B.; SCHMIDT-HANSEN, Ulrich. (2006), “The State and Corporatism. The Role of the State in the Development and Reproduction of 'the Danish Model'". Working Paper $n$ o 32. Copenhagen Business School International Center for Business and Politics.

KENWORTHY, Lane. (2004), Egalitarian Capitalism: Jobs, Incomes, and Growth in Affluent Countries. New York, Russell Sage Foundation.

. (2010), The Politics of Helping the Poor. University of Arizona. Mimeo.

KERSTENETZKY, Celia L. (2012), O Estado do Bem-Estar Social na Idade da Razão: A Reinvenção do Estado Social no Mundo Contemporâneo. Rio de Janeiro, Campus/Elsevier.

. (2014), "The Brazilian Social Developmental State: A Progressive Agenda in a (still) Conservative Political Society", in M. Williams (ed.), The End of the Developmental State? New York, Routledge.

; KERSTENETZKY, Jaques. (2014a), “The State as a Developmental Actor: State Forms for Social Transformation", in B. Currie-Alder et al. (eds.), International Development: Ideas, Experience, and Prospects. Oxford, Oxford University Press.

. (2014b), "Subsidiaridade e Universalismo como Princípios Organizativos do Estado Social", in K. Zeller, Panorama Socioeconômico do Brasil e suas Relações com a Economia Social de Mercado. Rio de Janeiro, Fundação Konrad Adenauer.

KRISTENSEN, Peer H. (2011), “The co-evolution of Experimentalist Business Systems and Enabling Welfare States: Nordic Countries in Transition", in Peer H. Kristensen; Kari Lilja (eds.), Nordic Capitalisms and Globalization: New Forms of Economic Organization and Welfare Institutions. Oxford, Oxford University Press.

KRUEGER, Anne O. (1990), "Government Failures in Development". The Journal of Economic Perspectives, vol. 4, no 3, pp. 9-23.

KUZNETS, Simon. (1955), "Economic Growth and Income Inequality". The American Economic Review, vol. 45, no 1, pp.1-28.

LIN, Justin Y. (2011), “New Structural Economics: A Framework for Rethinking Development". The World Bank Research Observer, vol. 26, no 2, pp. 193-221.

MEIER, Gerald M. (2001), "Introduction: Ideas for Development", in G. M. Meier; J. M. Stiglitz (eds.), Frontiers of Development Economics: The Future in Perspective. Washington, DC, World Bank/Oxford University Press.

NORTH, Douglass C. (1990), Institutions, Institutional Change and Economic Performance. Cambridge/New York, Cambridge University Press.

OBINGER, Herbert et al. (2010), Transformations of the Welfare State: Small States, Big Lessons. Oxford, Oxford University Press.

OECD (Organisation for Economic Co-operation and Development). (2008), Growing Unequal? Income Distribution and Poverty in OECD Countries. Paris, OECD Publishing.

. (2009), Social Expenditure Database. 2009. Disponível em http://www.oecd.org/ document/9/0,3746,en_2649_33933_38141385_1_1_1_1,00.html. Acessado em $13 / 10 / 2011$.

PRITCHETT, Lant M. et al. (2010), “Capability Traps? The Mechanisms of Persistent Implementation Failure". Working Paper no 234, Center for Global Development.

PRITCHETT, Lant M.; de WEIJER, Frauke. (2010), "Fragile States: Stuck in Capability Trap?". World Development Report 2011. Washington, DC, World Bank. 


\section{O Estado (de Bem-Estar Social) como Ator do Desenvolvimento}

RODRIK, Dani. (2000), “Institutions for High-Quality Growth: What They Are and How to Acquire Them". Working Paper 7540, National Bureau of Economic Research.

. (2006), “Goodbye Washington Consensus, Hello Washington Confusion? A Review of the World Bank's Economic Growth in the 1990s: Learning from a Decade of Reform". Journal of Economic Literature, vol. 43, pp. 973-987.

SCHMITTER, Philippe C. (1974), "Still the Century of Corporatism?". The Review of Politics, vol. 36, no 1, pp. 85-131.

SEN, Amartya. (1983), “Development: Which Way Now?". The Economic Journal, vol. 93, no 372 , pp. 745-762.

. (1989), "Development as Capability Expansion". Journal of Development Planning, vol. 19, pp. 41-58.

. (1999), Development as Freedom. New York, Knopf.

SINGH, Anoop et al. (2005), "Stabilization and Reform in Latin America: A Macroeconomic Perspective on the Experience since the Early 1990s". Occasional Paper no 238, International Monetary Fund, Washington, DC.

SOLIMANO, Andrès. (2012), Chile and the Neoliberal Trap. The post-Pinochet Era. Cambridge, Cambridge University Press.

SOOK, Woo M. (2004), “Explaining Early Welfare Policies in South Korea: Focusing on the Nexus between the State and the Business Sector". Development and Society, vol. 33, no 2, pp. 185-206.

STEWART, Frances et al. (2011), "Paths to Success: The Relationship between Human Development and Economic Growth". World Development, vol. 39, no4, pp. 506-522.

STREECK, Wolfgang. (2009), Re-forming Capitalism. Institutional Change in the German Political Economy. Oxford, Oxford University Press.

; HASSEL, Anke. (2004), "The Crumbling Pillars of Social Partnership", in H. Kitschelt; W. Streeck (eds.), Germany: Beyond the Stable State. London, Portland, Frank Cass.

VÉRON, René. (2001), “The 'New' Kerala Model: Lessons for Sustainable Development". World Development, vol. 29, no 4, pp. 601-617.

WADE, Robert. (2003), Governing the Market: Economic Theory and the Role of Government in East Asian Industrialization. Princeton, Princeton University Press.

WILLIAMSON, John (ed.). (1990), Latin American Adjustment How Much Has Happened? Washington, DC, Institute for International Economics.

. (2004), A Short History of the Washington Consensus. Trabalho apresentado na conferência From the Washington Consensus towards a New Global Governance. Barcelona, 24-25 de setembro.

WILLIAMSON, Oliver E. (1985), The Economic Institutions of Capitalism. New York/London, Free Press.

WOO-CUMINGS, Meredith. (1999), "Introduction: Chalmers Johnson and the Politics of Nationalism and Development", in M. Woo-Cumings (ed.), The Developmental State. Ithaca, Cornell University Press.

WORLD BANK. (1993), The East Asian Miracle. Economic Growth and Public Police. New York, Oxford University Press. 


\title{
RESUMO \\ O Estado (de Bem-Estar Social) como Ator do Desenvolvimento: Uma História das Ideias
}

Reconstruímos neste artigo uma história das ideias, abstratas ou incorporadas em práticas concretas, da ação estatal voltada ao desenvolvimento, da concepção de "Estados-poder" a "Estados de Bem-Estar", seguindo o fluxo e o refluxo de argumentos em favor da intervenção. Justificativas de intervenção baseadas na necessidade de superar descontinuidades econômicas são contrapostas a argumentos que apontam os riscos e antídotos da captura do Estado por interesses privados, bem como à abordagem mais ampla ao desenvolvimento de Amartya Sen. Experiências nacionais de desenvolvimento e de Estado de Bem-Estar Social são também rastreadas, como "ideias incorporadas". Identificamos uma defesa da intervenção do Estado que integra os campos econômico, político e social e aponta a democracia e o Estado de Bem-Estar como temas emergentes no discurso do desenvolvimento.

Palavras-chave: Estado desenvolvimentista; democracia; Estado de Bem-Estar; desenvolvimento econômico e social; formas de Estado

\author{
ABSTRACT \\ The (Welfare) State as an Actor of Development: A History of Ideas
}

This article reconstrues a history of ideas, whether abstract or incorporated into concreted practices, of state actions oriented toward development, from the conception of "power states" to "welfare states", following the ebb and flow of arguments in favor of intervention. Justifications of intervention based on the need to overcome economic disruptions are contrasted to arguments that point out the risks and antidotes to the capture of the State by vested interests, as well as Amartya Sen's broader approach to development. National experiences of development and of welfare states are also traced as "incorporated ideas". It was possible to identify a defense of State intervention integrating the economic, political and social fields and points toward democracy and the Welfare State as emerging subjects in the discourse of development.

Keywords: developmentalist states; democracy; Welfare Stare; economic and social development; state forms 


\section{RÉSUMÉ \\ L'État (Providence) en tant qu'Acteur de Développement: Une Histoire des Idées}

Nous reconstituerons dans cet article une histoire des idées, abstraites ou intégrées à des pratiques concrètes, de l'action étatique tournée vers le développement et des conceptions d'"État-pouvoir" et d'"État-Providence", en suivant le flux et le reflux des arguments en faveur de l'intervention publique. Aux justifications de cette intervention basées sur la nécessité de dépasser les discontinuités économiques s'opposent des arguments pointant les risques de capture de l'État par des intérêts privés, ainsi que l'approche plus large de développement chère à Amartya Sen. Les expériences nationales de développement et d'État-providence seront également prises en considération en tant qu'"idées incorporées". Nous avons identifié une défense de l'intervention de l'État qui intègre les champs économique, politique et social, et fait de la démocratie et de l'État-providence des thèmes émergents du discours du développement.

Mots-clés: État développementiste; démocratie; État-providence; développement économique et social; formes étatiques

\section{RESUMEN \\ El Estado (de Bienestar Social) como Actor del Desarrollo: Una Historia de las Ideas}

Reconstruimos en este artículo una historia de las ideas, abstractas o incorporadas en prácticas concretas, de acción estatal dirigidas al desarrollo, de la concepción de "Estados-poder" a "Estados de bienestar", siguiendo el flujo y el reflujo de argumentos favorables a la intervención. Las justificativas intervencionistas basadas en la necesidad de superar discontinuidades económicas son contrapuestas a argumentos que subrayan los riesgos y antídotos de la captura del Estado por intereses privados, bien como al enfoque más abarcador de Amartya Sen. Experiencias nacionales de desarrollo y de Estado de bienestar social también son rastreadas, como "ideas incorporadas". Identificamos, finalmente, una defensa de la intervención del Estado que integra los campos económico, político y social y apunta la democracia y el Estado de bienestar como temas emergentes en el discurso desarrollista.

Palabras clave: Estado desarrollista; democracia; Estado de bienestar; desarrollo económico y social; formas de Estado 